\title{
BMJ Open Statin use in adults at high risk of cardiovascular disease mortality: cross-sectional analysis of baseline data from The Irish Longitudinal Study on Ageing (TILDA)
}

\author{
Catriona Murphy, ${ }^{1}$ Kathleen Bennett, ${ }^{2}$ Tom Fahey, ${ }^{3}$ Emer Shelley, ${ }^{4}$ Ian Graham, ${ }^{5}$ \\ Rose Anne Kenny ${ }^{1}$
}

To cite: Murphy $C$, Bennett K, Fahey T, et al. Statin use in adults at high risk of cardiovascular disease mortality: cross-sectional analysis of baseline data from The Irish Longitudinal Study on Ageing (TILDA). BMJ Open 2015;5:e008017. doi:10.1136/bmjopen-2015008017

- Prepublication histor for this paper is available online. To view these files please visit the journal online (http://dx.doi.org/10.1136/ bmjopen-2015-008017).

Received 19 February 2015 Revised 29 May 2015 Accepted 25 June 2015

CrossMark

For numbered affiliations see end of article.

Correspondence to Dr Catriona Murphy; Catriona.murphy@tcd.ie

\section{ABSTRACT}

Objectives: This study aims to examine the extent to which statins are used by adults at high risk of cardiovascular disease (CVD) compared to European clinical guidelines. The high-risk groups examined are those with (1) known CVD, (2) known diabetes and (3) a high or very high risk ( $\geq 5 \%$ ) of CVD mortality based on Systematic COronary Risk Evaluation (SCORE).

Design: This study is cross-sectional in design using data from the first wave (2009-2011) of The Irish Longitudinal Study on Ageing (TILDA).

Setting and participants: The sample $(n=3372)$ is representative of community living adults aged 50-64 years in Ireland.

Results: Statins were used by $68.6 \%(95 \% \mathrm{Cl} 61.5 \%$ to $75.8 \%)$ of those with known CVD, $57.4 \%(95 \% \mathrm{Cl}$ $49.1 \%$ to $65.7 \%$ ) of those with known diabetes and by $19.7 \%(95 \% \mathrm{Cl} 13.0 \%$ to $26.3 \%)$ of adults with a SCORE risk $\geq 5 \%$. Over a third $(38.5 \%, 95 \% \mathrm{Cl} 31.0 \%$ to $46.0 \%)$ of those with known CVD, $46.8 \%(95 \% \mathrm{Cl}$ $38.4 \%$ to $55.1 \%$ ) of those with known diabetes and $85.2 \%(95 \% \mathrm{Cl} 79.3 \%$ to $91.1 \%)$ of those with a SCORE risk $\geq 5 \%$ were at or above the low-density lipoprotein cholesterol (LDL-C) target of $2.5 \mathrm{mmol} / \mathrm{L}$ specified in the 2007 European guidelines.

Conclusions: Despite strong evidence and clinical guidelines recommending the use of statins for secondary prevention, a gap exists between guidelines and practice in this cohort. It is also of concern that a low proportion of adults with a SCORE risk $\geq 5 \%$ were taking statins. A policy response that strengthens secondary prevention, and improves risk assessment and shared decision-making in the primary prevention of CVD is required.

\section{INTRODUCTION}

Cardiovascular disease (CVD) is the leading cause of mortality globally ${ }^{1}$ and accounts for about a third of all deaths in Ireland. $^{2}$ Dyslipidaemia, especially hypercholesterolaemia, plays a major role in the development of CVD.

\section{Strengths and limitations of this study}

- This is the first study to examine the use of statins in community living adults (50-64 years) at high risk of cardiovascular disease (CVD) in Ireland.

- Study strengths include the large nationally representative sample, structured collection of interview data and standardised protocols for objective health measures.

- Potential limitations include the reliance on selfreports of doctors' diagnosis of CVD and diabetes, and the absence of information on those that declined or discontinued statin treatment.

- Despite strong evidence on the benefits of statin use for prevention of CVD, this study reveals a gap between guidelines and practice in this group.

Evidence from randomised controlled trials has estimated that a $1 \mathrm{mmol} / \mathrm{L}$ individual level reduction in low-density lipoprotein cholesterol (LDL-C) is associated with a 20-25\% reduction in CVD mortality and non-fatal myocardial infarction, regardless of an individual's initial lipid profile. ${ }^{3} 4$ Lipid-lowering drugs include statins, fibrates, bile acid sequestrants, nicotinic acid and selective cholesterol absorption inhibitors. Statins not only reduce LDL-C but halt progression, and may contribute to regression of coronary atherosclerosis. ${ }^{56}$ Statins are, therefore, used as the drugs of first choice in patients with hypercholesterolaemia ${ }^{3}$ and for lowering LDL-C in the vast majority of individuals with a high risk of CVD and associated mortality. ${ }^{7}$ The role of statins in the secondary prevention of CVD morbidity and mortality is well established, resulting in clinical guidelines that recommend statin prescription to all adults with clinical evidence of 
CVD. ${ }^{8-11}$ Statins also play a role in the primary prevention of CVD for adults at high risk of CVD. This includes those with diabetes, ${ }^{8-10}$ those with familial hypercholesterolaemia $^{12}$ and those with a high or very high $(\geq 5 \%)$ Systematic COronary Risk Evaluation (SCORE) in combination with defined LDL-C threshold levels. ${ }^{3}$ European guidelines on CVD prevention in clinical practice, including the management of dyslipidaemia, were published in $2007^{12}$ and updated in $2012 .^{3}$

This study aims to examine the extent to which statins are used by adults (50-64 years) at high risk of CVD morbidity and mortality in Ireland compared to European clinical guidelines. The high-risk groups examined include those with: (1) known CVD, (b) known diabetes and (3) a high or very high risk $(\geq 5 \%)$ of CVD mortality based on SCORE. ${ }^{13}$

\section{METHODS}

\section{Design and data collection}

The study uses cross-sectional data from a nationally representative sample of community living adults aged 50 years and older in Ireland. The sample was recruited based on a national directory of residential addresses using the RANSAM system. ${ }^{14}$ The data were collected as part of the first wave of the Irish Longitudinal Study on Ageing (TILDA). All participants provided written informed consent.

Data were collected between October 2009 and July 2011. Participants took part in a face-to-face computerassisted personal interview in their home followed by a health assessment in a designated centre or in their home. Further details are available elsewhere on the health assessment element of this study. ${ }^{15}$

\section{Measurements}

Participants were asked "Has a doctor ever told you that you have any of the following conditions?" CVD (angina, myocardial infarction, coronary artery bypass surgery, stroke or transient ischaemic attack (TIA)) and diabetes (types I and II) classification were based on participant responses to this question or a self-report of having undergone an angioplasty or stent insertion procedure. Information on current smoking status was collected during the interview.

Current medication use, including statin therapy, was recorded by the interviewer during the home-based interview and cross-checked using medication labels. Good agreement has been demonstrated in this cohort between self-report and pharmacy dispensing records for lipid-modifying agents $(\kappa=0.73,95 \%$ CI 0.69 to $0.77) .{ }^{16}$ Medication was classified according to the WHO Anatomical Therapeutic Chemical classification system. All 3-Hydroxy-3-methylglutaryl coenzyme A (HMG-CoA)reductase inhibitors (statins) were coded as C10AA, and those in combination with other lipid-modifying agents and with other combinations, coded as C10B, were combined to create a single statin variable.
Blood pressure was measured during the health assessment by a nurse according to a standard protocol. A digital automated oscillometric blood pressure monitor (Omron M10-IT, Omron Inc, Kyoto, Japan) was used to measure blood pressure while the respondent was seated comfortably in an upright position after a period of rest. Blood pressure was recorded twice while seated with a timed interval of 1 min between readings. The mean systolic blood pressure obtained from these two measurements was used in SCORE.

Non-fasting venous blood was drawn to estimate total cholesterol, high-density lipoprotein cholesterol (HDL-C) and triglycerides. LDL-C was estimated based on the Friedewald equation. ${ }^{17}$ Total cholesterol and LDL-C were grouped according to targets set in the $2007^{12}$ guidelines and threshold categories for drug intervention in the $2012^{3}$ guidelines.

\section{High-risk groups}

SCORE estimates the 10-year risk of first fatal atherosclerotic event in those aged $40-64$ years. ${ }^{13}$ The youngest TILDA participants were 50 years old; therefore, this study is limited to those aged 50-64 years. SCORE was developed to provide a risk scoring system for use in the clinical management of cardiovascular risk in participants without known CVD in European clinical practice. It includes the following risk factors: age, sex, systolic blood pressure, total cholesterol and smoking status. Risk equations have been developed for 'low risk' and 'high risk' countries ${ }^{3}$ based on cut-off points for CVD and diabetes mortality in men and women in 2008. Ireland was classified as 'low risk'; therefore, the corresponding risk equations were applied to the TILDA data in this study.

Those with known CVD, diabetes mellitus and familial hypercholesterolaemia are considered to be at high risk. ${ }^{3} 12$ Those with familial hypercholesterolaemia (LDL-C $>6 \mathrm{mmol} / \mathrm{L}, \mathrm{n}=13$ ) were not analysed in this study due to the small number found. The remainder of the sample was grouped into four categories according to the SCORE protocol: low risk $(<1 \%)$, moderate risk $(\geq 1 \%$ and $<5 \%)$, high risk $(\geq 5 \%$ and $<10 \%)$ and very high risk $(\geq 10 \%)$ of CVD mortality. The high-risk and very high risk groups were collapsed into a single SCORE $\geq 5 \%$ high-risk group.

\section{Covariates}

Demographic covariates included age, sex and highest educational attainment (primary, secondary and tertiary). Access to primary healthcare was assessed using entitlement to a means tested medical card which provides free access to general practitioner (GP) care and heavily subsidised prescribed medicines. Frequency of GP visits was recorded as the number of visits to the GP in the previous 12 months. 


\section{Statistical analysis}

We calculated the prevalence and 95\% CIs for CVD, diabetes, and high or very high SCORE risk in the age group of 50-64 years. Respondent groups were compared using $\chi^{2}$ tests for categorical variables and t tests for continuous variables. Generalised linear models with binomial distribution, log link function and robust standard errors were used to determine the association between medical card status and statin utilisation in the three groups at high risk of CVD mortality, adjusting for age, sex, level of education and frequency of GP visits. Unadjusted and adjusted risk ratios (RRs) and 95\% CIs are presented.

Estimates of the absolute number of individuals suboptimally treated with statins in the high-risk groups were calculated based on the 2012 guidelines ${ }^{3}$ and using population data from Census 2011. ${ }^{18}$ Survey weights based on age, sex and educational attainment were applied to reduce non-response bias to the interview stage of the survey. Additional weights based on health and demographic factors were applied to increase the representativeness of the sample used in the analysis. Statistical significance was set at $\mathrm{p}<0.05$. The statistical software Stata/MP V.12.1 was used to conduct the analyses.

\section{RESULTS}

The overall household response rate was $62 \%$. In total, 8175 respondents completed the home-based interview,
$57.1 \%(\mathrm{n}=4668)$ of these respondents were aged $50-64$ years (figure 1$)$. Of these, $75.3 \% \quad(n=3517)$ completed a health assessment $(91.6 \%$ in a health assessment centre, $8.4 \%$ in the respondent's home). Owing to small numbers, the high-risk group with LDL-C $>6 \mathrm{mmol} / \mathrm{L} \quad(\mathrm{n}=13)$ were excluded from the analysis as were those with missing data $(n=132)$. The final sample size for analysis consisted of 3372 individuals with full risk factor data available.

Characteristics of the sample by sex are provided in table 1 . The mean age of the sample was $56.7 \quad(\mathrm{SD}=4.2)$ years and $45 \%$ were men. Almost one-fifth were current smokers (18.3\%), and smoking was equally distributed between men and women. Total cholesterol, LDL-C and HDL-C levels were higher in women compared to men. In contrast, triglycerides, systolic and diastolic blood pressure levels were higher in men compared to women.

\section{High-risk groups}

Three high-risk groups for CVD mortality were identified: those with known CVD, those with known diabetes and those at high or very high $(\geq 5 \%)$ SCORE risk. Of those aged $50-64$ years, $4.9 \%$ (95\% CI $4.1 \%$ to $5.6 \%$ ) $(\mathrm{n}=166)$ had known CVD, including 23 with diabetes. A further $4.2 \%$ (95\% CI $3.5 \%$ to $4.8 \%) \quad(n=141)$ had self-reported diabetes without CVD (figure 1).

SCORE 10-year risk of CVD mortality was estimated in those without evidence of CVD or diabetes $(n=3065)$. The majority were classified as low risk $(40.9 \%, 95 \%$ CI

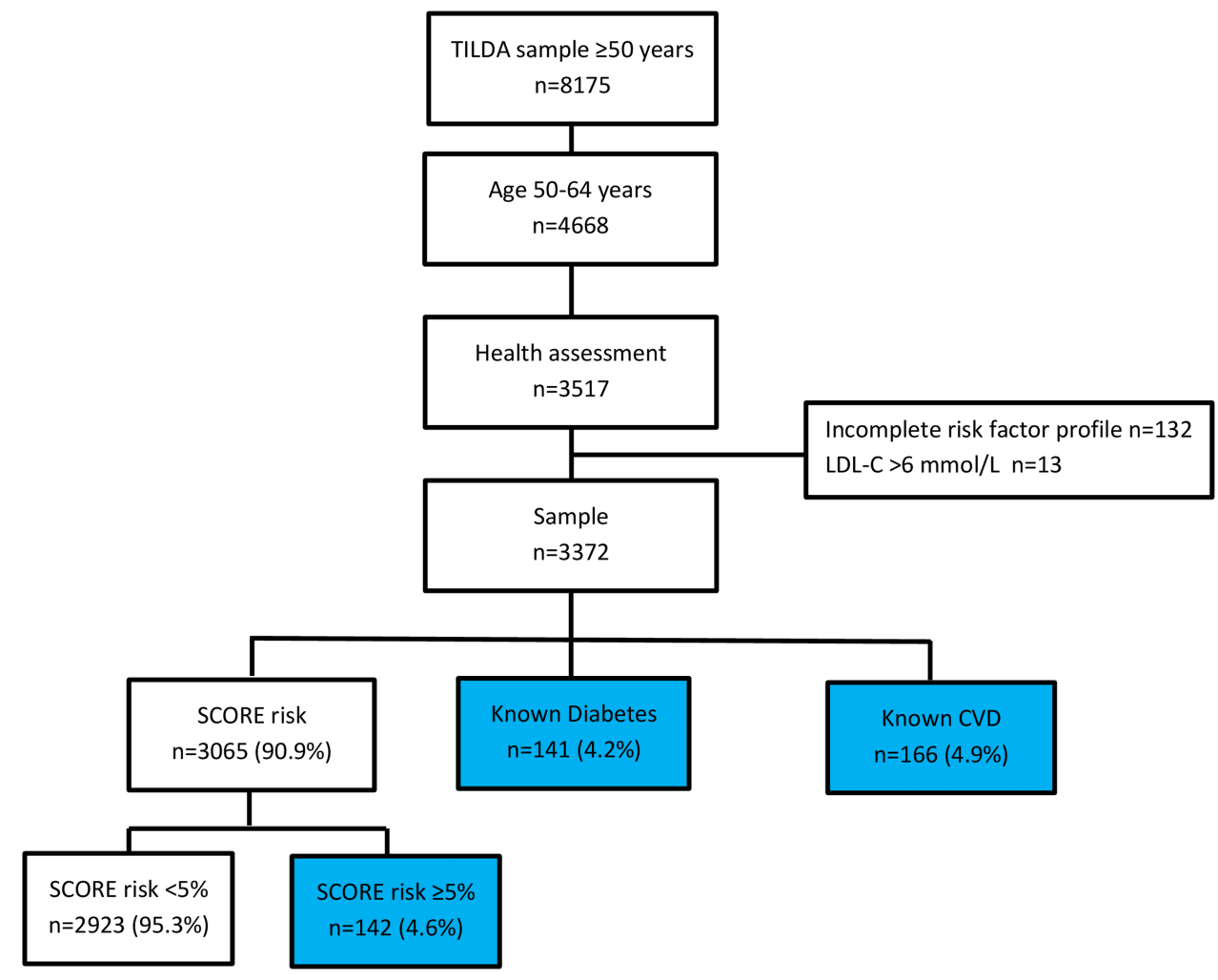

Figure 1 Flow chart of the number of participants included in the analysis (CVD, cardiovascular disease; LDL-C, low-density lipoprotein cholesterol; SCORE, Systematic COronary Risk Evaluation; TILDA, The Irish Longitudinal Study on Ageing). 
Table 1 Characteristics of the sample (50-64 years TILDA wave 1)

\begin{tabular}{|c|c|c|c|}
\hline & $\begin{array}{l}\text { Males } \\
(n=1515)\end{array}$ & $\begin{array}{l}\text { Females } \\
(n=1857)\end{array}$ & $\begin{array}{l}\text { Total } \\
(n=3372)\end{array}$ \\
\hline Age, years & $56.6(4.2)$ & $56.7(4.2)$ & $56.7(4.2)$ \\
\hline \multicolumn{4}{|l|}{ Education } \\
\hline Primary & 19.1 & 16.1 & 17.5 \\
\hline Secondary & 46.4 & 44.8 & 45.5 \\
\hline Tertiary & 34.3 & 39.0 & 36.9 \\
\hline Medical card & 21.6 & 27.1 & 24.6 \\
\hline Current smoker & 18.2 & 18.4 & 18.3 \\
\hline $\begin{array}{l}\text { Total cholesterol, } \\
\mathrm{mmol} / \mathrm{L}\end{array}$ & $5.0(0.9)$ & $5.4(0.9)$ & $5.3(1.0)$ \\
\hline LDL-C, mmol/L & $2.9(0.9)$ & $3.1(0.9)$ & $3.0(0.9)$ \\
\hline HDL-C, $\mathrm{mmol} / \mathrm{L}$ & $1.3(0.3)$ & $1.7(0.4)$ & $1.5(0.4)$ \\
\hline $\begin{array}{l}\text { Triglycerides, } \\
\mathrm{mmol} / \mathrm{L}\end{array}$ & $2.0(1.3)$ & $1.5(0.9)$ & $1.7(1.1)$ \\
\hline $\begin{array}{l}\text { Systolic BP, } \\
\mathrm{mm} \mathrm{Hg}\end{array}$ & 137.1 (17.3) & $127.6(17.9)$ & $131.9(18.3)$ \\
\hline $\begin{array}{l}\text { Diastolic BP, } \\
\mathrm{mm} \mathrm{Hg}\end{array}$ & $85.3(10.7)$ & $81.4(10.9)$ & $83.1(11.0)$ \\
\hline Statins & 24.0 & 21.2 & 22.5 \\
\hline
\end{tabular}

$39.2 \%$ to $42.6 \%)(\mathrm{n}=1255)$ or moderate risk $(54.4 \%$, $95 \%$ CI $52.6 \%$ to $56.1 \%$ ) (n=1668), with a smaller proportion at high risk $(4.0 \%, 95 \%$ CI $3.3 \%$ to $4.7 \%)$ $(\mathrm{n}=124)$ or very high risk $(0.6 \%, 95 \%$ CI $0.3 \%$ to $0.8 \%)$ $(\mathrm{n}=18)$. The pattern of risk differed between men and women. The low-risk group was comprised mostly of women, whereas men were in the majority in the moderate, high and very high risk groups. When the highrisk and very high risk groups were combined, $4.6 \%$ $(95 \%$ CI $3.8 \%$ to $5.3 \%) \quad(n=142)$ of those classified using SCORE had a $\geq 5 \%$ 10-year risk of CVD mortality (figure 1).

\section{Statin use in the groups at high risk}

LDL-C levels and statin use were examined in the three groups at high risk (table 2). The proportion taking statins was $68.6 \%$ (95\% CI $61.5 \%$ to $75.8 \%)$ in those with known CVD, $57.4 \%$ (95\% CI $49.1 \%$ to $65.7 \%$ ) in those with known diabetes and $19.7 \%(95 \%$ CI $13.0 \%$ to $26.3 \%)$ in those with a high SCORE risk $(\geq 5 \%)$ (table 2$)$.

A further breakdown of statin utilisation according to prior diagnosis of angina, myocardial infarction, stroke, TIA and revascularisation procedure is documented in figure 2. Statin use ranged from a high of $80.3 \%(95 \%$ CI $69.6 \%$ to $91.0 \%$ ) in those who reported a revascularisation procedure to a low of $51.6 \%$ (95\% CI $32.9 \%$ to $70.2 \%$ ) in those with a self-reported diagnosis of a TIA. In individuals who reported experiencing one or more CVD events, $78.6 \%$ (95\% CI $68.1 \%$ to $89.2 \%$ ) were on statin therapy (figure 2).
Bivariate and multivariable models were used to examine the relationship between statin utilisation and medical card status in each of the three groups at high risk (table 3). No association was found between medical card status and statin utilisation in those with known CVD or in those with known diabetes. In the group with SCORE risk $\geq 5 \%$, those with a medical card were twice as likely to be taking statins (adjusted $\mathrm{RR}=2.20,95 \%$ CI 1.13 to 4.26 ) compared to those without a medical card (table 3 ).

\section{Lipid profiles in high-risk groups compared to guideline targets in 2007}

Over a third (38.5\%, 95\% CI $31.0 \%$ to $46.0 \%)$ of those with known CVD, $46.8 \%$ (95\%CI $38.4 \%$ to $55.1 \%$ ) of those with known diabetes and $85.2 \%(79.3 \%-91.1 \%)$ of those with a SCORE risk $\geq 5 \%$ were at or above the LDL-C target of $2.5 \mathrm{mmol} / \mathrm{L}$ specified in the 2007 European guidelines. ${ }^{12}$ Close to half $(45.7 \%, 95 \%$ CI $38.1 \%$ to $53.4 \%$ ) of those with known CVD, $50.3 \%$ (95\% CI $42.0 \%$ to $58.7 \%$ ) of those with known diabetes and $90.8 \%$ (95\% CI $86.0 \%$ to $95.6 \%$ ) of those with a SCORE risk $\geq 5 \%$ were at or above the total cholesterol target of $4.5 \mathrm{mmol} / \mathrm{L}$ (table 2).

\section{Lipid profiles in high-risk groups compared to guideline targets in 2012}

The target LDL-C for those with CVD was reduced to $<1.8 \mathrm{mmol} / \mathrm{L}$ in the 2012 guidelines. ${ }^{3}$ Just over a quarter of the CVD group $(27.7 \%, \mathrm{n}=46)$ were at the recommended target LDL-C level for secondary prevention populations using the updated guidelines published within a year of data collection completion (not shown). These updated guidelines recommend immediate drug intervention at the LDL-C threshold of $\geq 1.8 \mathrm{mmol} / \mathrm{L}$ in those with a very high $(\geq 10 \%)$ SCORE risk and a threshold of $\geq 2.5 \mathrm{mmol} / \mathrm{L}$ in those with a high $(\geq 5 \%$ and $<10 \%)$ SCORE risk. Using these cut-off, $87 \%(\mathrm{n}=123)$ of those with a SCORE risk $\geq 5 \%$ were identified as requiring immediate drug intervention based on these recent guidelines.

Population data from Census $2011^{18}$ were used to calculate the absolute difference between the observed number of high-risk individuals in the age group of 50-64 years on statin therapy and the expected number based on the 2012 guidelines $^{3}$ (table 4). In a total population (50-64 years) of 737694 , we estimate that 51885 individuals were on suboptimal statin treatment compared to the guidelines. This includes 11715 with known CVD, 13398 with known diabetes and 26772 with a SCORE risk $\geq 5 \%$.

\section{DISCUSSION}

\section{Statement of the principal findings}

The main finding in this study was that statin utilisation for secondary prevention in those aged 50-64 years was lower than expected based on European CVD 


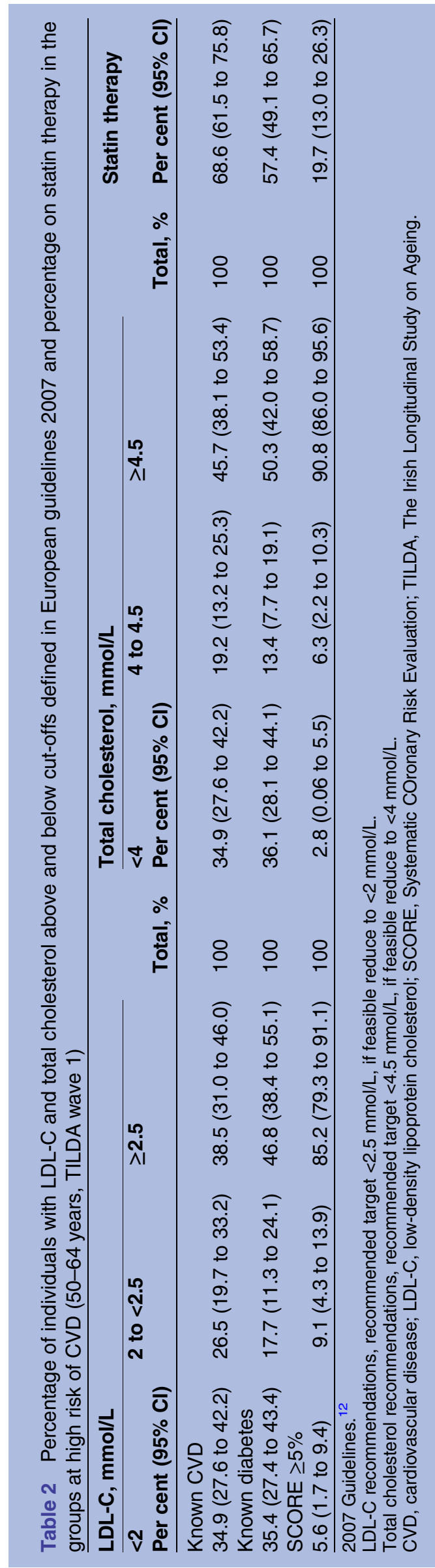

guidelines. In those with known CVD, $68.6 \%$ were utilising statins and this figure only increased to $78.6 \%$ in those who had experienced more than one type of CVD event. Statin use for primary prevention in those at high risk of CVD was also low, with $57.4 \%$ of those with known diabetes and $19.7 \%$ of those with a SCORE risk of $\geq 5 \%$ using a statin.

\section{Secondary prevention}

Despite strong evidence and clinical guidelines supporting the use of statins for secondary prevention in conjunction with lifestyle interventions, a gap exists between European CVD guidelines and clinical practice in this cohort. Research has demonstrated poor control of risk factors in those with coronary heart disease, ${ }^{19}{ }^{20}$ despite improvements in the use of cardioprotective medication. The most recent EUROASPIRE IV study conducted across 24 European countries found that statins were used by $85.7 \%$ of patients, 6 months after an initial coronary artery bypass graft, percutaneous coronary intervention or acute coronary syndrome. ${ }^{20}$ Robust incentives such as the Quality Outcomes Framework (QOF) which rewards general practice for quality care have resulted in an increase in statin prescription across the UK. ${ }^{21}$ Participation in the QOF is voluntary and almost all practices take part in it. In England, the use of lipid-lowering medication in a community cohort of adults aged 35 years and older who self-reported ischaemic heart disease or stroke was $79 \%$ in men and $72 \%$ in women in 2011. ${ }^{22}$ Recent evidence from the Action on Secondary Prevention through Intervention to Reduce Events (ASPIRE-2-PREVENT) survey conducted in a stratified random sample of hospitals and general practices in the UK revealed that over $90 \%$ of those with coronary heart disease were on statins. ${ }^{23}$

Previous Irish research has also demonstrated improved statin usage in patients with established coronary heart disease enrolled on Heartwatch, a programme of secondary prevention in primary care. ${ }^{24}$ One-fifth of general practices participated in Heartwatch, inviting their patients to attend on a quarterly basis for secondary prevention in addition to usual care. Statin usage increased from $78.5 \%$ at baseline in 2003 to $89.9 \%$ in 2005 among those enrolled on the programme. ${ }^{25}$ The current research, conducted 4 years later, shows evidence of lower levels of statin utilisation and failure to achieve guideline targets in a representative sample of adults with known CVD living in the community. The findings reveal that statin use among those with known CVD was lowest in participants who had experienced a stroke or TIA. This finding is of concern given the strong evidence provided by the Stroke Prevention by Aggressive Reduction in Cholesterol Levels (SPARCL) study to support the use of high-dose statin therapy to reduce adverse outcomes. ${ }^{26}$ The policy implications of these findings are that secondary prevention should be strengthened at primary care level to reduce the risk of future CVD events in this population. 


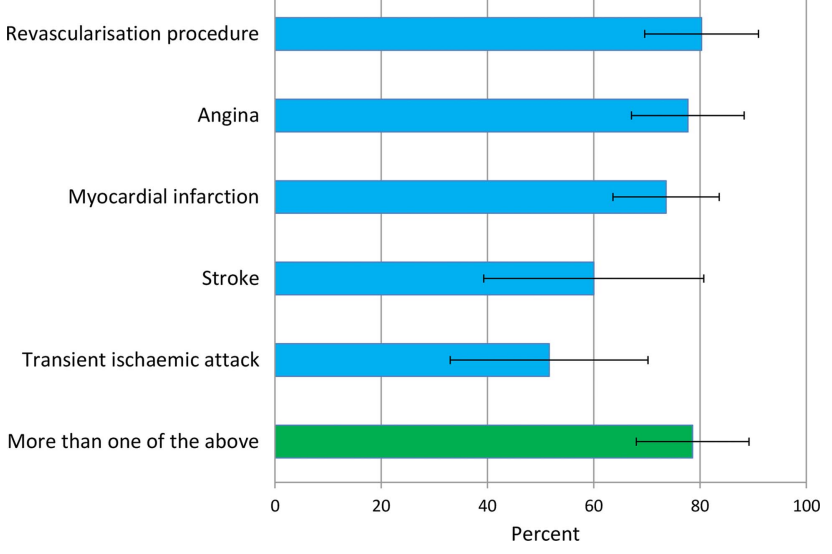

Figure 2 Proportion utilising statins by cardiovascular disease (CVD) event type (50-64 years, The Irish Longitudinal Study on Ageing (TILDA) wave 1).

\section{Primary prevention}

In this study, the use of statins for the primary prevention of CVD was examined only in those classified as high or very high risk $(\geq 5 \%)$ based on SCORE. There is ongoing debate on the benefits and risks of using statins for the primary prevention of CVD in those at low absolute risk of CVD, ${ }^{927} 28$ and this issue is not addressed in this paper.

In patients without established CVD but with CVD risk factors including diabetes, statins are associated with reductions in all-cause mortality and incidence of major coronary and cerebrovascular events. ${ }^{29}$ Primary prevention of CVD in the clinical setting requires a focus on lifestyle modification ${ }^{30}$ and individualised risk assessment. This may take the form of a routine assessment of a defined population group similar to the Health Check provided in the UK for all adults aged $40-74$ years $^{31}$ or risk assessment on an opportunistic basis as is the current practice in Ireland. A Cochrane review found that general health checks did not reduce morbidity or mortality for cardiovascular causes and insufficient evidence was found to support routine screening of the population. ${ }^{32}$ Results from the recent Inter99 study

Table 3 Risk ratio of utilising a statin for those with a medical card in the groups at high risk of CVD (50-64 years, TILDA wave 1)

\begin{tabular}{llllll}
\hline & \multicolumn{2}{l}{ Model 1 } & \multicolumn{2}{l}{ Model 2 } \\
\cline { 2 - 3 } \cline { 5 - 6 } & $\mathbf{R R}$ & $\mathbf{9 5 \%} \mathbf{C l}$ & & Adj RR & $\mathbf{9 5 \%} \mathbf{C l}$ \\
\hline Known CVD & 0.97 & 0.78 to 1.19 & & 0.91 & 0.72 to 1.15 \\
Known diabetes & 1.28 & 0.97 to 1.70 & & 1.24 & 0.91 to 1.69 \\
SCORE $\geq 5 \%$ & $2.02^{*}$ & 1.04 to 3.89 & $2.2^{*}$ & 1.13 to 4.26 \\
\hline
\end{tabular}

Model 1: unadjusted.

Model 2: adjusted for age, sex, education and frequency of GP visits in the previous 12 months.

${ }^{*} \mathrm{p}<0.05$.

Adj RR, adjusted risk ratio; CVD, cardiovascular disease; GP, general practitioner; SCORE, Systematic COronary Risk Evaluation; TILDA, The Irish Longitudinal Study on Ageing.

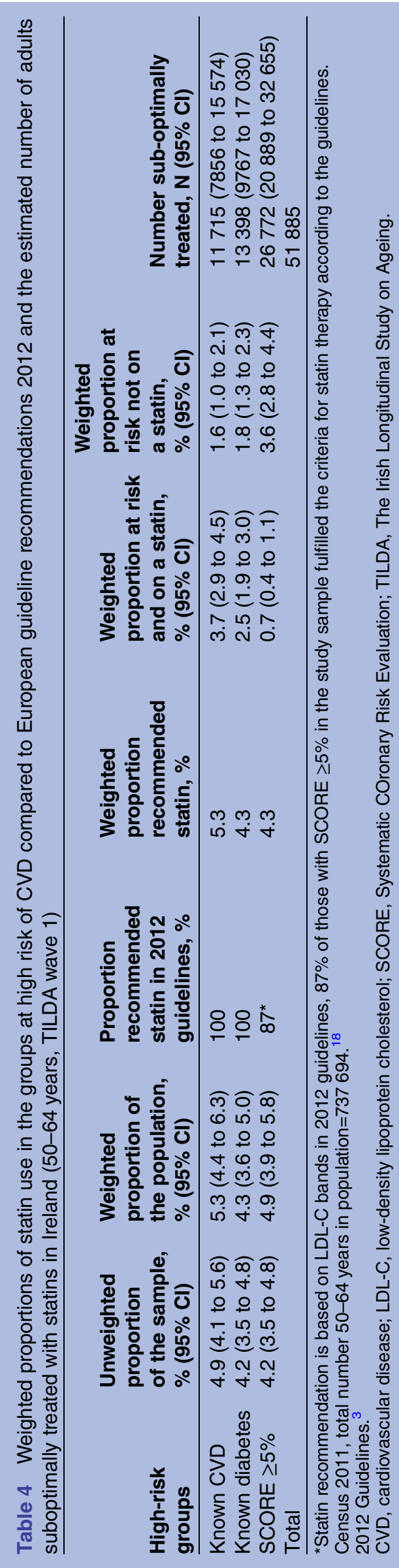


concur, finding that an individually tailored intervention programme with screening for risk and an individually tailored lifestyle intervention had no effect on ischaemic heart disease, stroke or mortality at the population level after 10 years. ${ }^{33}$ In the absence of evidence to support risk assessment of the entire population, opportunistic assessment using appropriate risk assessment tools is required to identify those at highest risk of future CVD who may benefit from primary prevention advice. The findings of the risk assessment together with clinical practice guidelines can be used to guide discussions between physicians and patients with regard to the benefits and risks of long-term statin therapy.

\section{Suboptimal medication}

Non-adherence to prescribed medications may explain some of the low level of statin utilisation found in our study and the failure to achieve target levels of LDL-C. Non-adherence to prescribed statins is known to lead to adverse outcomes and higher costs of care. ${ }^{34}$ Adherence has been found to fall after the acute phase following a CVD event and is low in those taking statins for chronic coronary artery disease. ${ }^{35}$ The global Reduction of Atherothrombosis for Continued Health (REACH) study examined long-term adherence to medication in patients with atherothrombotic disease. The study revealed that almost half of patients were deemed adherent to guideline recommended medications over a 4-year period. ${ }^{36}$ Reasons for non-adherence to statins may include statin intolerance ${ }^{37}$ and cost. $^{38}$ The reported incidence of statin intolerance is variable with observational studies reporting muscular symptoms in $10.5 \%$ of patients on high-dose statin therapy. ${ }^{39}$ The majority of individuals in this study with a SCORE risk $\geq 5 \%$ were at high risk $(\geq 5 \%$ and $<10 \%)$ as opposed to very high risk $(\geq 10 \%)$ of GVD mortality. It is, therefore, possible that patient preference and willingness to accept lifelong medication in the absence of overt disease had a role to play in the low level of statin use in this primary prevention group.

In our study, a quarter of the sample was eligible for a medical card which entitled them to free GP visits and heavily subsidised prescribed medications. The remainder were required to pay, out of pocket, for GP visits (approximate cost $€ 50-70$ per visit) and prescribed medication. No evidence was found to suggest that medical card status was associated with statin utilisation in the groups with known CVD or diabetes. However, the positive association found between medical card status and statin utilisation in those at high SCORE risk suggests that financial barriers act as a deterrent to primary prevention in this high-risk group. Previous research on eligibility for free GP care in Ireland has demonstrated that those with a medical card are more likely to visit their GP and to visit more frequently than private patients. ${ }^{40} \mathrm{In}$ the primary prevention context, this provides more opportunity for those with a medical card to avail of opportunistic risk assessment. Previous research in this cohort has similarly demonstrated that cardiovascular medication is utilised more frequently by those with a medical card. ${ }^{4142}$ The cost of statins during the study period was high; only $8.5 \%$ of statins used by this cohort were generic ${ }^{43}$ resulting in high cost for individuals prescribed statins and without access to a medical card.

The low level $(19.7 \%)$ of statin use for primary prevention in those with a SCORE risk $\geq 5 \%$ may have resulted from a combination of insufficient risk assessment or failure to adhere to clinical guidelines. Evidence that guidelines are sporadically applied was demonstrated in EUROASPIRE. ${ }^{44}$ Although physicians have been found to support the use of guidelines and are aware of the need to consider a combination of CVD risk factors, less than half have been found to use guidelines or risk calculators to determine total risk in European studies. ${ }^{45} 46$ Barriers to CVD guideline implementation include time constraints; ${ }^{45-47}$ patient compliance $;{ }^{45}$ financial limitations, including lack of GP remuneration; $;^{45}{ }^{46}$ government health policy; ${ }^{45}$ lack of perceived usefulness, including inadequate knowledge of the risk scoring systems; ${ }^{47}$ and fear of over-use of medical therapies. ${ }^{48}$

\section{Strengths and limitations of the study}

The strengths of this study include the large nationally representative sample of community-living adults which allows us to generalise our findings to the population in Ireland; the structured collection of interview data, including medication data; and the use of standardised protocols for measurements taken during the health assessment. Non-fasting blood was analysed for lipid levels; this may be considered a limitation. Research at the pilot stage of TILDA found that mean total cholesterol and LDL-C did not differ by fasting allocation ${ }^{49}$ and recent research recommends re-evaluating the recommendation that patients fast before obtaining a lipid panel as non-fasting LDL-C has been found to have similar prognostic value to fasting LDL-C. ${ }^{50}$

While TILDA aimed to generate a nationally representative sample, the non-response rate to the survey may have introduced some selection bias. It is likely that responders had a better risk factor profile compared to non-responders thus providing a more optimistic view of risk factor management in this population. The availability of a home and centre-based health assessment reduced the selection bias associated with the health assessment component of the survey.

This study is limited as it relies on self-reports of doctors' diagnosis of CVD and diabetes which may underestimate the true prevalence of these conditions. Previous research on this cohort found a lower prevalence of hypertension and atrial fibrillation on selfreport when compared to objective measures. ${ }^{51}{ }^{52}$ Markers of organ damage are not available in the TILDA data set; some asymptomatic individuals with organ damage may, therefore, have been misclassified to a lower level of risk than should be the case. In this research it is not possible to identify individuals who 
were formally risk stratified or those engaged in lifestyle changes before consideration of pharmacological measures. Neither it is possible to identify those who discontinued a statin due to intolerance nor those who declined statin treatment following risk assessment and consultation with their medical practitioner.

\section{CONCLUSION}

This is the first study to examine the use of statins in those at high risk of CVD in a nationally representative sample of adults aged 50-64 years in Ireland. Despite strong evidence and clinical guidelines supporting the use of statins for secondary prevention of CVD, this study reveals a gap between guidelines and clinical practice in this group. An immediate policy response is required to strengthen secondary prevention for those with existing CVD. For the remainder of the population without evidence of CVD, population strategies for primary prevention are required as well as opportunistic risk assessment to identify those at high risk of future CVD in order to establish best practice in primary prevention.

\section{Author affiliations \\ ${ }^{1}$ Department of Medical Gerontology, Trinity College, Dublin, Ireland 2Department of Pharmacology and Therapeutics, Trinity College, Dublin, Ireland \\ ${ }^{3}$ Department of General Practice, HRB Centre for Primary Care Research, Royal College of Surgeons in Ireland Medical School, Dublin, Ireland ${ }^{4}$ Department of Public Health, Health Service Executive, Dublin, Ireland ${ }^{5}$ Department of Cardiology, Tallaght Hospital, Dublin, Ireland}

Acknowledgements The authors are grateful to all of the TILDA respondents who gave generously of their time in participating in this study. They also acknowledge the contribution of our collaborator Dr Angie Brown at the Irish Heart Foundation and Dr Marie Therese Cooney for providing assistance with the Stata code for SCORE.

Contributors $\mathrm{CM}$ was the lead researcher and was involved in the design, implementation, analysis and reporting of the study. ES, TF, KB, IG and RAK provided substantial contributions to the conception and design of the work, and all have read and approved the final manuscript.

Funding This work was supported by the Irish Health Research Board Interdisciplinary Capacity Enhancement Award [grant number: ICE/2012/7]. TILDA is funded by the Irish Government (Department of Health), Atlantic Philanthropies and Irish Life. The funders had no involvement in the analysis or preparation of this paper.

Competing interests None declared.

Ethics approval Trinity College Research Ethics Committee.

Provenance and peer review Not commissioned; externally peer reviewed.

Data sharing statement Researchers interested in using TILDA data may access the data for free from the following sites: Irish Social Science Data Archive (ISSDA) at University College Dublin http://www.ucd.ie/issda/data/ tilda/ ; Interuniversity Consortium for Political and Social Research (ICPSR) at the University of Michigan http://www.icpsr.umich.edu/icpsrweb/ICPSR/ studies/34315

Open Access This is an Open Access article distributed in accordance with the Creative Commons Attribution Non Commercial (CC BY-NC 4.0) license, which permits others to distribute, remix, adapt, build upon this work noncommercially, and license their derivative works on different terms, provided the original work is properly cited and the use is non-commercial. See: http:// creativecommons.org/licenses/by-nc/4.0/

\section{REFERENCES}

1. World Health Organization. Global Health Estimates 2014 Summary Tables Deaths by Cause, Age and Sex, 2000-2012. Secondary Global Health Estimates 2014 Summary Tables Deaths by Cause, Age and Sex, 2000-2012. 2014. http://www.who.int/healthinfo/ global burden disease/estimates/en/index1.html

2. Department of Health. Health in Ireland: key trends 2012. Dublin: Department of Health, 2012.

3. Perk J, De Backer G, Gohlke H, et al. 'European Guidelines on cardiovascular disease prevention in clinical practice (version 2012)' The Fifth Joint Task Force of the European Society of Cardiology and Other Societies on Cardiovascular Disease Prevention in Clinical Practice (constituted by representatives of nine societies and by invited experts). Eur Heart J 2012;33:2126.

4. Baigent C, Keech A, Kearney PM, et al. Efficacy and safety of cholesterol-lowering treatment: prospective meta-analysis of data from 90,056 participants in 14 randomised trials of statins. Lancet 2005;366:1267-78.

5. Nicholls SJ, Ballantyne CM, Barter PJ, et al. Effect of two intensive statin regimens on progression of coronary disease. N Engl J Med 2011;365:2078-87.

6. Nissen SE, Nicholls SJ, Sipahi I, et al. Effect of very high-intensity statin therapy on regression of coronary atherosclerosis: the asteroid trial. JAMA 2006;295:1556-65.

7. Reiner Z. Resistance and intolerance to statins. Nutr Metab Cardiovasc Dis 2014;24:1057-66.

8. Reiner Ž, Catapano AL, De Backer G, et al. ESC/EAS Guidelines for the management of dyslipidaemias: the Task Force for the management of dyslipidaemias of the European Society of Cardiology (ESC) and the European Atherosclerosis Society (EAS). Eur Heart J 2011;32:1769-818.

9. Taylor F, Ward K, Moore TH, et al. Statins for the primary prevention of cardiovascular disease. Cochrane Database Syst Rev 2011;(1): CD004816.

10. National Institute for Health and Clinical Excellence. Statins for the prevention of cardiovascular events. London: National Institute for Health and Clinical Excellence, 2008.

11. Stone NJ, Robinson J, Lichtenstein AH, et al. 2013 ACC/AHA Guideline on the treatment of blood cholesterol to reduce atherosclerotic cardiovascular risk in adults: a report of the American College of Cardiology/American Heart Association Task Force on Practice Guidelines. Circulation 2013;129(25 Suppl 2):S1-45.

12. Graham I, Atar D, Borch-Johnsen K, et al. European guidelines on cardiovascular disease prevention in clinical practice: executive summary. Fourth Joint Task Force of the European Society of Cardiology and other societies on cardiovascular disease prevention in clinical practice (constituted by representatives of nine societies and by invited experts). Eur J Cardiovasc Prev Rehabil 2007;14 (Suppl 2):E1-40.

13. Conroy RM, Pyörälä K, Fitzgerald AP, et al. Estimation of ten-year risk of fatal cardiovascular disease in Europe: the SCORE project. Eur Heart J 2003;24:987-1003.

14. Whelan BJ. RANSAM: a national random sampling design for Ireland. Econ Soc Rev 1979;10:169-74.

15. Cronin $\mathrm{H}$, O'Regan $\mathrm{C}$, Finucane $\mathrm{C}$, et al. Health and aging: development of The Irish Longitudinal Study on Ageing health assessment. J Am Geriatr Soc 2013;61:S269-78.

16. Richardson K, Kenny RA, Peklar J, et al. Agreement between patient interview data on prescription medication use and pharmacy records in those aged older than 50 years varied by therapeutic group and reporting of indicated health conditions. J Clin Epidemiol 2013;66:1308-16.

17. Martin SS, Blaha MJ, Elshazly MB, et al. Friedewald-estimated versus directly measured low-density lipoprotein cholesterol and treatment implications. J Am Coll Cardiol 2013;62:732-9.

18. Central Statistics Office. StatBank CD211: enumerated population by sex age group and census year. Cork: CSO, 2012.

19. Cooney MT, Kotseva K, Dudina A, et al. Determinants of risk factor control in subjects with coronary heart disease: a report from the EUROASPIRE III investigators. Eur J Prev Cardiol 2013;20:686-91.

20. Kotseva K, Wood D, De Bacquer D, et al. EUROASPIRE IV: a European Society of Cardiology survey on the lifestyle, risk factor and therapeutic management of coronary patients from 24 European countries. Eur J Prev Cardiol 2015 [Epub ahead of print 16 Feb 2015].

21. Alabbadi I, Crealey G, Turner K, et al. Statin prescribing in Northern Ireland and England pre and post introduction of the quality and outcomes framework. Pharm World Sci 2010;32:43-51.

22. Mindell J, Craig R, eds. Health survey of England 2011: health, social care and lifestyles, chapter 2 cardiovascular disease. NatCen Social Research, 2011. 
23. Kotseva K, Jennings CS, Turner EL, et al. ASPIRE-2-PREVENT: a survey of lifestyle, risk factor management and cardioprotective medication in patients with coronary heart disease and people at high risk of developing cardiovascular disease in the UK. Heart 2012;98:865-71.

24. Fitzpatrick P, Fitz-Simon N, Lonergan M, et al. Heartwatch: the effect of a primary care-delivered secondary prevention programme for cardiovascular disease. Eur J Cardiovasc Prev Rehabil 2011;18:129-35.

25. Bennett K, Jennings S, Collins $\mathrm{C}$, et al. Heartwatch: a secondary prevention progamme in primary care in Ireland. Eur $J$ Cardiovasc Prev Rehabil 2008;15:651-6.

26. The Stroke Prevention by Aggressive Reduction in Cholesterol Levels (SPARCL) Investigators. High-dose atorvastatin after stroke or transient ischemic attack. N Engl J Med 2006;355:549-59.

27. Taylor F, Huffman MD, Macedo AF, et al. Statins for the primary prevention of cardiovascular disease. Cochrane Database Syst Rev 2013;(1):CD004816.

28. Abramson JD, Rosenberg HG, Jewell N, et al. Should people at low risk of cardiovascular disease take a statin? BMJ 2013;347:f6123.

29. Brugts JJ, Yetgin T, Hoeks SE, et al. The benefits of statins in people without established cardiovascular disease but with cardiovascular risk factors: meta-analysis of randomised controlled trials. BMJ 2009;338:b2376.

30. National Institute for Health and Care Excellence. Lipid Modification cardiovascular risk assessment and the modification of blood lipids for the primary and secondary prevention of cardiovascular disease. NICE clinical guideline 181. NICE clinical guideline 181. National Institute for Health and Care Excellence, 2014.

31. Fenton K, Kelly MP, Newton J, et al. NHS Health Check our approach to the evidence. Local Government Association, NICE NHS England, 2013.

32. Krogsbøll LT, Jørgensen KJ, Larsen CG, et al. General health checks in adults for reducing morbidity and mortality from disease: Cochrane systematic review and meta-analysis. BMJ 2012;345:e7191.

33. Jørgensen $\mathrm{T}$, Jacobsen RK, Toft $\mathrm{U}$, et al. Effect of screening and lifestyle counselling on incidence of ischaemic heart disease in general population: Inter99 randomised trial. BMJ 2014;348:g3617.

34. Ho PM, Bryson C, Rumsfeld JS. Medication adherence: its importance in cardiovascular outcomes. Circulation 2009;119:3028-35

35. Jackevicius CA, Mamdani M, Tu JV. Adherence with statin therapy in elderly patients with and without acute coronary syndromes. JAMA 2002;288:462-7.

36. Rodriguez F, Cannon CP, Steg PG, et al. Predictors of long-term adherence to evidence-based cardiovascular disease medications in outpatients with stable atherothrombotic disease: findings from the REACH Registry. Clin Cardiol 2013;36:721-7.

37. Auer J, Sinzinger H, Franklin B, et al. Muscle- and skeletal-related side-effects of statins: tip of the iceberg? Eur J Prev Cardiol 2014 [Epub ahead of print 17 Sep 2014].

38. Gupta R, Islam S, Mony $\mathrm{P}$, et al. Socioeconomic factors and use of secondary preventive therapies for cardiovascular diseases in South
Asia: the PURE study. Eur J Prev Cardiol 2014 [Epub ahead of print 18 Jun 2015].

39. Bruckert E, Hayem G, Dejager S, et al. Mild to moderate muscular symptoms with high-dosage statin therapy in hyperlipidemic patients -the PRIMO study. Cardiovasc Drugs Ther 2005;19:403-14.

40. Nolan A, Nolan B. Eligibility for free GP care, "need" and GP visiting in Ireland. Eur J Health Econ 2008;9:157-63.

41. Murphy CM, Kearney PM, Shelley EB, et al. Hypertension prevalence, awareness, treatment and control in the over 50 s in Ireland: evidence from The Irish Longitudinal Study on Ageing. $J$ Public Health (Oxf) 2015 [Epub ahead of print 28 Apr 2015].

42. Richardson K, Kenny RA, Bennett K. The effect of free health care on polypharmacy: a comparison of propensity score methods and multivariable regression to account for confounding. Pharmacoepidemiol Drug Saf 2014;23:656-65.

43. Murphy $\mathrm{C}$, Moore $\mathrm{P}, \mathrm{Mc}$ Hugh $\mathrm{S}$, Health and social care utilisation. In: Nolan A, O'Regan C, Dooley C, et al. eds. The over 50 s in a changing Ireland: economic circumstances, health and well-being. Dublin: The Irish Longitudinal Study on Ageing, 2014:124-52.

44. Zannad F, Dallongeville J, Macfadyen RJ, et al. Prevention of cardiovascular disease guided by total risk estimations-challenges and opportunities for practical implementation: highlights of a CardioVascular Clinical Trialists (CVCT) Workshop of the ESC Working Group on CardioVascular Pharmacology and Drug Therapy. Eur J Prev Cardiol 2012;19:1454-64.

45. Graham IM, Stewart M, Hertog MG. Factors impeding the implementation of cardiovascular prevention guidelines: findings from a survey conducted by the European Society of Cardiology. Eur J Cardiovasc Prev Rehabil 2006;13:839-45.

46. Reiner Z, Sonicki Z, Tedeschi-Reiner E. Physicians' perception, knowledge and awareness of cardiovascular risk factors and adherence to prevention guidelines: the PERCRO-DOC survey. Atherosclerosis 2010;213:598-603.

47. Dallongeville J, Banegas JR, Tubach F, et al. Survey of physicians practices in the control of cardiovascular risk factors: the EURIKA study. Eur J Prev Cardiol 2012;19:541-50.

48. Hobbs FD, Jukema JW, Da Silva PM, et al. Barriers to cardiovascular disease risk scoring and primary prevention in Europe. QJM 2010;103:727-39.

49. Kearney PM, O'Regan $\mathrm{C}$, Cronin $\mathrm{H}$, et al. Effect of fasting on participation in clinical research among older people. Eur Geriatr Med 2011:2:187-9.

50. Doran B, Guo Y, Xu J, et al. Prognostic value of fasting versus nonfasting low-density lipoprotein cholesterol levels on long-term mortality: insight from the National Health and Nutrition Examination Survey III (NHANES-III). Circulation 2014;130:546-53.

51. Frewen J, Finucane $\mathrm{C}$, Cronin $\mathrm{H}$, et al. Factors that influence awareness and treatment of atrial fibrillation in older adults. QJM 2013;106:415-24

52. Mosca I, Bhuachalla BN, Kenny RA. Explaining significant differences in subjective and objective measures of cardiovascular health: evidence for the socioeconomic gradient in a population-based study. BMC Cardiovas Disord 2013;13:64. 